\title{
ANALISIS KESOPANAN BAHASA LEECH \& GRICE: MANIFESTASI STRUKTUR DALAM PERISTIWA MELUNAS RINDU (POLITENESS ANALYSIS OF LEECH AND GRICE: THE STRUCTURAL PATTERNS OF POLITENESS MANIFESTED IN THE NOVEL MELUNAS RINDU)
}

Sara Binti Beden \& Indirawati Zahid Department of Malay Language, Academy of Malay Studies,

Universiti of Malaya, Kuala Lumpur (sra7109@yahoo.com.my, indirawati@um.edu.my)

\begin{abstract}
The purpose of this research is to classify and structuralize the pattern of politeness in the novel Melunas Rindu, the literature text used by the form four students in Zone 4 (Johor, Sabah, Sarawak and Wilayah Persekutuan Labuan). The pattern of politeness is depicted through various occurrences and dialogues between the characters in the novel. When practising the pattern of politeness, a suitable structure is used according to a specific occurrence. Thus, the research data reflects the analysis done on this pattern of politeness. The dialogues of the main and supporting characters of the novel from Chapter 12 were analysed. The two models of Leech Politeness Principle (1983) and Grice Model of Communication (1975) were used to analyse the dialogues. This research used library research, text analysis and quantitative methods. The findings showed that only four Leech maxims and only two Grice maxims were fulfilled. The findings also showed that the Leech maxims were not able to stand alone in portraying the politeness pattern as a combination of maxims to form specific patterns is needed. In certain cases, the Leech maxims were completed with the presence of the Grice maxims. In addition, the application of structure in the politeness pattern for each occurrence was diversified. It can be concluded that the politeness pattern and its structure of politeness exist because of specified events.
\end{abstract}

Keywords: dialogues, Politeness Principles, Cooperative Principles, structures, combination pattern, maxim combination pattern 


\section{Pendahuluan}

Kesopanan semasa berwacana atau berbahasa akan menjadi penentu untuk mencitrakan diri dan keperibadian seseorang. Oleh itu, kesopanan berbahasa tidak boleh dipandang remeh kerana penggunaan bahasa yang sopan berhubung erat dengan sosiobudaya dan konteks pengguna dan penggunaannya. Kesopanan berbahasa turut dipengaruhi budaya yang melatari kehidupan sesebuah masyarakat. Seseorang yang berbahasa dengan sopan seperti lemah lembut, tertib, jelas, tidak berlebih-lebihan dan tidak menyinggung perasaan orang lain dianggap sebagai orang yang "tahu bahasa" dan beradab dalam budaya masyarakatnya.

Kesopanan berbahasa bukan sahaja mencitrakan keperibadian malahan memanifestasikan citra dan identiti bangsanya. Hal ini demikian kerana kesopanan dapat menggambarkan jati diri dan menjadi asas kejatidirian Melayu yang terpuji (Tenas Effendi, 2011) sementara Mior Ahmad Noor Mior Hamzah (2003 : 155) berpendapat bahawa ketamadunan akan berkembang kembali dengan suburnya jika bangsa Melayu itu punya jati diri. Kedua-dua pandangan ini mencerminkan bahawa kekuatan jati diri amat signifikan untuk menjadi sebuah bangsa yang bertamadun dan mempunyai peradaban yang tinggi.

Aspek kesopanan berbahasa bukan sahaja signifikan dalam penggunaan bahasa yang bersifat lisan semata-mata malahan memainkan peranan yang penting dalam penggunaan bahasa yang bersifat tulisan. Sesebuah teks harus memaparkan penggunaan bahasa yang sopan agar menjadi wadah yang berkesan untuk mentarbiah generasi muda khasnya para murid. Sesebuah karya sastera yang bermutu tidak akan meminggirkan aspek kesopanan berbahasa sebagai cerminan keintelektualan pengarangnya. Justeru, langkah Kementerian Pendidikan Malaysia mengintegrasikan bahan sastera dalam mata pelajaran Bahasa Melayu merupakan tindakan yang wajar dan bijak untuk memenuhi hasrat Falsafah Pendidikan Kebangsaan (FPK) iaitu menekankan pengembangan potensi anak didik secara seimbang daripada segi jasmani, rohani, intelektual dan emosional (Naffi Mat, 2006).

Pengintegrasian teks sastera secara sistematik dalam mata pelajaran Bahasa Melayu mulai tahun 2000 sehinggalah sekarang bukan sahaja memudahkan para guru malahan memberikan manfaat kepada para murid dalam mengenali karya dan pengarangnya. Perkara yang lebih mustahak ialah kandungan teks sastera yang sarat dengan falsafah dan pemikiran yang dijelmakan oleh pengarang. Menurut Azman Ismail (2010: 15), sesebuah karya kreatif tanpa mengira genre mempunyai hubungan yang erat dengan persoalan moral, intelektual, keagamaan, etika, suara kemanusiaan, keluhuran dan kedamaian. Beliau turut berpendapat bahawa melalui kehalusan dan estetika, sesebuah karya sastera mampu membangkitkan nilai yang bersesuaian dengan fitrah manusia yang dahagakan keindahan, kedamaian, keharmonian dan 
mengungkapkan cara sesebuah masyarakat berfikir. Pandangan ini bertepatan dengan hasrat murni dalam FPK yang hendak melahirkan generasi yang mempunyai daya intelektual dan daya fikir yang tinggi tanpa mengesampingkan keseimbangan emosi, rohani dan jasmani (Kementerian Pendidikan, 2001).

Langkah mengintegrasikan teks sastera dalam subjek Bahasa Melayu amat bertepatan dengan usaha untuk menerapkan nilai murni kerana implementasi ini merupakan suatu mekanisme dalam pengajaran dan pembelajaran yang akhirnya akan menampakkan hasil yang efektif dan faedah yang tidak ternilai kepada generasi muda khasnya remaja. Hakikatnya, golongan remaja mempunyai tanggungjawab dan peranan yang amat penting dalam penerusan dan pengekalan institusi kemasyarakatan di negara kita (Haris Abd Wahab, 2004).

\section{Objektif}

Ojektif utama kajian ini adalah untuk menganalisis dan menstruktur kesopanan berbahasa dalam novel Melunas Rindu berdasarkan Prinsip Kesopanan Leech (1983) dan Prinsip Kerjasama Grice (1975).

\section{Metodologi Kajian}

Kajian ini menggunakan tiga kaedah, iaitu kaedah penyelidikan kepustakaan, kaedah analisis teks dan analisis kualitatif dan kuantitatif. Kajian kepustakaan melibatkan pembacaan dan pengumpulan bahan-bahan yang berkaitan dengan tajuk kajian. Sumber utama yang bakal digunakan banyak terdapat dalam bentuk bertulis seperti buku, majalah, jurnal, akhbar, kertas-kertas kerja seminar dan latihan ilmiah.

Analisis teks melibatkan pemilihan watak yang terlibat bagi dijadikan fokus kajian. Pengkategorian dibuat dengan memilih dialog yang diujarkan oleh watak utama dan watak sampingan. Dialog-dialog tersebut dikeluarkan dan akan melalui proses pelabelan atau pengekodan.

Data dikod berdasarkan tajuk buku, bab (jumlah halaman dalam satu-satu bab), nama watak yang melafazkan dialog, halaman dan nombor dialog mengikut urutan dalam sesebuah bab. Misalnya, MR-B1(9)-Fu-H6-D1/5. MR bermaksud Melunas Rindu, B1(9) bermakna Bab Satu dan angka sembilan dalam kurungan merujuk kepada jumlah halaman dalam Bab Satu, singkatan Fu bagi nama watak yang melafazkan dialog iaitu Fuad, H6 ialah halaman enam dan D1/5 pula ialah dialog satu daripada lima dialog yang dilafazkan oleh watak Fuad dalam Bab Satu. Tujuan pengekodan adalah untuk memudahkan proses pengenalpastian data analisis. Seterusnya, dialog dikelompokkan berdasarkan peristiwa tertentu sebelum dianalisis. Kajian ini hanya menggunakan dialog yang dilafazkan oleh dua watak, iaitu Fuad watak utama dan watak sampingan, iaitu Farhana hanya 
menggunakan 23 dialog (dari halaman 126-128). Jumlah 23 dialog ini bukanlah jumlah mutlak bilangan dialog, sebaliknya dirujuk sebagai bentuk lafaz seseorang watak yang boleh menyamai jumlah satu ayat atau bentuk lafaz seseorang watak yang melebihi jumlah satu ayat dalam sesuatu peristiwa

Analisis dilakukan dengan mengenal pasti kata kunci yang digunakan dalam dialog antara watak berdasarkan peristiwa tertentu dengan memberi fokus terhadap penggunaan kata, ungkapan dan ayat yang bersesuaian dengan padanan maksim-maksim dalam PS Leech dan PK Grice. Analisis kuantitatif pula akan memperlihatkan jumlah dan peratusan kesopanan berbahasa yang dipaparkan dalam bentuk jadual untuk memperjelaskan lagi dapatan kajian. Kaedah kualitatif diaplikasikan apabila dapatan analisis dihuraikan dengan menggunakan pendekatan pragmatik kerana pragmatik ialah kajian penggunaan bahasa berdasarkan konteks.

\section{Komponen Sastera (Komsas) dalam Mata Pelajaran Bahasa Melayu}

Komsas dalam mata pelajaran Bahasa Melayu merupakan integrasi bahan sastera seperti novel, antologi cerpen, antologi sajak dan puisi tradisional, antologi prosa klasik dan antologi drama. Melunas Rindu karya Hartini Hamzah merupakan salah sebuah novel yang diintegrasikan dalam Komsas. Novel ini merupakan novel yang telah dipilih oleh panel penilai untuk dijadikan bahan Komsas di peringkat sekolah menengah dan digunakan oleh para pelajar Tingkatan Empat di Zon 4 (Johor, Sarawak, Sabah dan Wilayah Persekutuan Labuan). Novel ini mengandungi 19 bab dengan ketebalan 209 halaman. Novel ini diterbitkan oleh Utusan Publications \& Distributor Sdn. Bhd. pada tahun 2009 untuk edisi murid. Novel ini pernah memenangi tempat pertama kategori Novel Remaja Hadiah Sastera Utusan Melayu \& Public Bank 1998. Kedudukan penggunaan novel tingkatan empat mengikut zon terdapat dalam Jadual 1 yang berikut:

\begin{tabular}{|l|l|}
\hline Genre Novel & Zon \\
\hline $\begin{array}{l}\text { Azfa Hanani karya Halis Azhan } \\
\text { Mohd. Hanafiah }\end{array}$ & $\begin{array}{l}\text { Zon 1: Perlis, Kedah, Pulau Pinang } \\
\text { dan Perak }\end{array}$ \\
\hline $\begin{array}{l}\text { Papa ... (Akhirnya Kau Tewas Jua) } \\
\text { Karya Deana Yusof }\end{array}$ & $\begin{array}{l}\text { Zon 2: Selangor, Negeri Sembilan, } \\
\text { Wilayah Persekutuan Kuala Lumpur } \\
\text { dan Wilayah Persekutuan Putrajaya }\end{array}$ \\
\hline Renyah karya Gunawan Mahmood & $\begin{array}{l}\text { Zon 3: Melaka, Pahang, Terengganu } \\
\text { dan Kelantan }\end{array}$ \\
\hline $\begin{array}{l}\text { Melunas Rindu karya Hartini } \\
\text { Hamzah }\end{array}$ & $\begin{array}{l}\text { Zon 4: Johor, Sarawak, Sabah dan } \\
\text { Wilayah persekutuan Labuan }\end{array}$ \\
\hline
\end{tabular}

Sesebuah karya sastera yang dipilih untuk bacaan dan kajian serta penghayatan para pelajar sudah tentu memenuhi kriteria yang ditetapkan oleh 
Pusat Perkembangan Kurikulum sejak bermulanya penyerapan teks Komsas secara terancang pada tahun 2000. Langkah ini diambil setelah mengkaji kandungan dalam sesebuah karya sastera yang sudah tentu mengandungi nilainilai murni sebagai wadah untuk mentarbiah dan menyemai unsur-unsur yang membina sama ada dari segi jasmani, rohani, emosi dan intelek seperti yang tercakup dalam Falsafah Pendidikan Kebangsaan. Menurut Haris Abd Wahab (2004: 72) sekiranya individu dalam masyarakat dididik dengan baik dan sempurna maka lahirlah kelompok masyarakat yang berilmu pengetahuan dan berkeupayaan mencapai kesejahteraan diri selain memberi sumbangan terhadap keharmonian dan kemakmuran negara. Kesinambungannya, guru yang mengajar dari pelbagai mata pelajaran haruslah berperanan memberi kesedaran tentang nilai dan moral dalam proses pengajaran dan pembelajaran agar memberi kesan yang positif dalam pembangunan diri murid (Mohamad Khairi Othman \& Asmawati Suhid, 2010).

Sesebuah karya sastera turut mementingkan pertuturan secara bersopan atau santun ketika watak berdialog dengan orang lain di samping mendedahkan penggunaan bahasa yang berlapik. Justeru, integrasi teks sastera dalam mata pelajaran Bahasa Melayu dapat membantu para murid mempertajam minda dan meningkatkan kepekaan mereka dalam berkomunikasi.

\section{Model Kesopanan Leech (1983) \& Model Kerjasama Grice (1975)}

Leech (1983) telah memperkenalkan satu prinsip yang dikenali dengan Prinsip Kesopanan (PS). PS Leech lebih menekankan faktor budaya masyarakat, psikologi penutur-pendengar dalam menyampaikan maksud dengan berkesan. PS ini lebih menekankan tingkah laku dan persoalan beradab yang menghubungkan dua pihak dalam sesuatu proses komunikasi, iaitu antara diri sendiri yakni penutur dan orang lain yakni pendengar. Leech (1983) memberi penekanan pada prinsip yang memaksimumkan keuntungan, kesepakatan, rasa hormat dan sikap belas kasihan kepada orang lain dengan meminimumkan atau mengabaikan perkaraperkara tersebut terhadap diri sendiri. Maksim-maksim Leech adalah seperti berikut:

i. Maksim Kebijaksanaan (Tact) ialah maksim yang meminimumkan kos bagi orang lain dan memaksimumkan manfaat kepada orang lain.

ii. Maksim Kedermawanan (Generosity) ialah maksim yang meminimumkan manfaat bagi diri sendiri dan memaksimumkan kos bagi diri sendiri atau dengan kata lain menguntungkan orang lain.

iii. Maksim Sokongan (Approbation) ialah maksim yang meminimumkan cacian terhadap orang lain dan memaksimumkan pujian terhadap orang lain. 
iv. Maksim Kerendahan Hati (Modesity) ialah maksim yang meminimumkan pujian terhadap diri sendiri dan memaksimumkan cacian terhadap diri sendiri.

v. Maksim Persetujuan (Agreement) ialah maksim yang meminimumkan perbalahan antara diri sendiri dengan orang lain dan memaksimumkan persetujuan antara diri sendiri dengan orang lain bagi mencapai kesepakatan.

vi. Maksim Simpati (Sympathy) ialah maksim yang meminimumkan antipati antara diri sendiri dengan orang lain dan memaksimumkan simpati antara diri sendiri dengan orang lain.

Grice (1975) telah mengemukakan PK, iaitu prinsip atau tatacara yang perlu dipatuhi oleh penutur-penutur dalam perbualan mereka untuk menghasilkan satu komunikasi yang berkesan dengan kewujudan kerjasama kedua-dua belah pihak yang mengambil bahagian dalam perbualan tersebut. Maksim-maksim Grice dapat memberi makna yang mendalam dalam perbualan. Khan Qaisar \& Ali Bughio Faraz (2012) turut memperkatakan hal ini, iaitu:

"... the maxim is generally flouted on the surface level but at the deeper level, such flouting gives rise to implicatures. Such implicatures in turn render the conversation lively and more meaningful."

Empat maksim yang dikemukakan oleh Grice dan menjadi peraturan bagi mengawal perbualan ialah pertama, Maksim Kuantiti yang memerlukan pemberian maklumat yang sempurna, iaitu (i) memberi maklumat yang informatif dan mencukupi dan (ii) jangan memberi maklumat yang berlebihan daripada yang diperlukan. Kedua, Maksim Kualiti yang memerlukan pemberian maklumat yang betul, iaitu (i) tidak menyebut sesuatu yang anda tidak tahu atau benar dan (ii) tidak menyebut sesuatu yang anda tidak tahu dalil atau kesahihan buktinya. Ketiga, Maksim Pertalian yang memerlukan maklumat yang relevan, iaitu (i) maklumat yang disampaikan haruslah berkaitan dan mempunyai pertalian dan keempat Maksim Cara yang menyatakan sesuatu dengan cara yang betul dan mudah difahami, iaitu (i) tidak taksa (ii)tidak kabur (iii) jelas (iv) tertib. Justeru, kajian ini akan menggabungkan kedua-dua model untuk menganalisis data berdasarkan peristiwa dalam Bab 12 novel ini bagi memperlihatkan kesopanan berbahasa yang digunakan. 


\section{Penganalisisan Data}

Penganalisisan terhadap data-data kajian dengan menggunakan kedua-dua model ini memperlihatkan pembentukan tiga pola kombinasi maksim, iaitu (i) pola kombinasi Maksim Kebijaksanaan + Kerendahan Hati + Persetujuan + Kuantiti, (ii) pola kombinasi Maksim Kebijaksanaan + Kerendahan Hati + Persetujuan dan (iii) pola kombinasi Maksim Kebijaksanaan + Sokongan + Kerendahan Hati + Relevan seperti yang terdapat dalam Jadual 2 yang berikut:

\begin{tabular}{|l|l|l|c|c|}
\hline Prinsip & Peristiwa & Pola Kombinasi Maksim & $\begin{array}{c}\text { Jumlah } \\
\text { Dialog }\end{array}$ & $\begin{array}{c}\text { Peratus } \\
\text { (\%) }\end{array}$ \\
\hline \multirow{2}{*}{$\begin{array}{l}\text { Kesopanan } \\
\text { Leech/ } \\
\text { Kerjasama } \\
\text { Grice }\end{array}$} & Peristiwa 1 & $\begin{array}{l}\text { Kebijaksanaan+Kerendahan } \\
\text { Hati } \\
\text { + Persetujuan+Kuantiti }\end{array}$ & 14 & 60.87 \\
\cline { 2 - 5 } & Peristiwa 2 & $\begin{array}{l}\text { Kebijaksanaan+Kerendahan } \\
\text { Hati+Persetujuan }\end{array}$ & 4 & 17.39 \\
\hline JUMLAH & 3 & $\begin{array}{l}\text { Kebijaksanaan+Sokongan+Ker } \\
\text { endahan Hati+Relevan }\end{array}$ & 5 & 21.74 \\
\hline
\end{tabular}

Jadual 2 menunjukkan tiga pola kombinasi maksim yang terbentuk berdasarkan 3 peristiwa dalam Bab 12 ini. Penganalisisan tersebut menunjukkan pola kombinasi Maksim Kebijaksanaan + Kerendahan Hati + Persetujuan + Kuantiti dalam peristiwa 1 diwakili 14 dialog, iaitu sebanyak 60.87 peratus dan pola kombinasi maksim Kebijaksanaan + Kerendahan Hati + Persetujuan dalam peristiwa 2 pula diwakili 4 dialog, iaitu 17.39 peratus manakala pola kombinasi maksim Kebijaksanaan + Sokongan + Kerendahan Hati + Relevan dalam peristiwa 3 diwakili 5 dialog, iaitu 21.74 peratus. Sementara itu, analisis turut memperlihatkan struktur pola kesopanan berbahasa yang bervariasi kerana setiap peristiwa komunikasi mempunyai objektif komunikasi yang berbeza-beza.

\section{Pola dan Struktur Kesopanan Berbahasa Leech (1983) \& Leech (1975)}

Terdapat tiga pola kombinasi maksim yang terbentuk berdasarkan analisis terhadap tiga peristiwa dalam data-data kajian. Huraian analisis pola-pola kombinasi maksim dan struktur peristiwa kesopanan adalah seperti berikut: 
(i)

\section{Pola Kombinasi Maksim Kebijaksanaan + Kerendahan Hati + Persetujuan + Kuantiti-Peristiwa 1: Fuad Memberi Kad Harijadi kepada Farhana}

Pola kombinasi Maksim Kebijaksanaan+Kerendahan Hati+Persetujuan+Kuantiti ditandai kata kunci yang tertentu. Maksim Kebijaksanaan ditandai pemilihan kata yang tepat untuk memanggil rakan sekerja manakala Maksim Kerendahan Hati ditandai sikap merendah diri dan mencaci diri sendiri. Sementara Maksim Persetujuan ditandai dengan kewujudan kesepakatan yang tinggi dalam perbualan dan Maksim Kuantiti pula ditandai sumbangan maklumat yang mencukupi dalam memenuhi permintaan atau pertanyaan. Kesemua dialog ini dianalisis berdasarkan peristiwa dalam novel ini. Pola kombinasi Maksim Kebijaksanaan+Kerendahan Hati+Persetujuan+Kuantiti ini dapat dilihat dalam peristiwa Fuad memberi kad harijadi kepada Farhana seperti dalam Jadual 3 berikut:

\begin{tabular}{|l|l|}
\hline \multicolumn{1}{|c|}{ Pola Kombinasi Maksinab } & Kebijaksanaan+Kerendahan Hati+Persetujuan+Kuantiti \\
\hline MR-B12(13)-Fu-H126-D1/37 & Ana ... Hari ni kau ada dapat kad tak? \\
MR-B12(13)-Fa-H126-D1/32 & Ada \\
MR-B12(13)-Fu-H126-D2/37 & Warna apa? \\
MR-B12(13)-Fa-H126-D2/32 & Merah jambu. \\
MR-B12(13)-Fu-H126-D3/37 & Cantik tak? \\
MR-B12(13)-Fa-H126-D3/32 & Cantik. \\
MR-B12(13)-Fu-H126-D4/37 & Kau tahu siapa yang bagi? \\
MR-B12(13)-Fa-H126-D4/32 & Tahu. \\
MR-B12(13)-Fu-H126-D5/37 & Siapa? \\
MR-B12(13)-Fa-H126-D5/32 & Engkaulah. \\
MR-B12(13)-Fu-H126-D6/37 & Ya ... Betul. Murah saja, empat ringgit setengah. \\
MR-B12(13)-Fa-H127-D6/32 & Ya? Siapa tanya? \\
MR-B12(13)-Fu-H127-D8/37 & Eh, kau tak tanya ya? Aku ingat kau tanya tadi. Kau suka tak? \\
MR-B12(13)-Fa-H127-D7/32 & Tentulah aku suka. Kau tahu sebab apa aku suka? Sebab, kau \\
& yang bagi! \\
\hline
\end{tabular}

Perbualan dalam peristiwa ini mematuhi Maksim Kebijaksanaan + Kerendahan Hati + Persetujuan + Kuantiti. Maksim Kebijaksanaan dikenal pasti melalui penggunaan kata ganti nama yang sesuai untuk memanggil rakan sekerja yang sudah akrab seperti $\boldsymbol{a} \boldsymbol{k} \boldsymbol{u}$ dan $\boldsymbol{k a} \boldsymbol{u}$ yang digunakan oleh Fuad dan Farhana. Penggunaan kata ganti nama $\boldsymbol{a} \boldsymbol{k} \boldsymbol{u}$ dan $\boldsymbol{k a} \boldsymbol{u}$ dalam konteks hubungan keduaduanya mencerminkan kesopanan berbahasa. Penggunaan kata ganti nama peribadi seperti Ana dalam peristiwa ini turut menggambarkan pemilihan kata yang sesuai untuk menyapa rakan. Pemilihan kata ganti nama yang sesuai dan 
tepat dalam berkomunikasi dapat memaksimumkan manfaat kepada pendengar yang sekali gus memanifestasikan kesopanan berbahasa.

Maksim Kerendahan Hati dipatuhi dalam peristiwa ini berdasarkan dialog MR-B12(13)-Fu-H126-D6/38 Murah saja, empat ringgit setengah oleh Fuad. Ungkapan murah saja dalam dialog ini mencerminkan kerendahan hati Fuad kerana sanggup mencaci diri sendiri dengan mengaku bahawa dia membeli kad yang murah dengan harga empat ringgit setengah. Fuad sanggup memaksimumkan cacian terhadap diri sendiri dengan mengakui kelemahan diri walaupun pada hakikatnya mampu membeli kad yang lebih mahal.

Maksim Persetujuan dalam peristiwa ini ditandai persetujuan secara langsung dalam dialog MR-B12(13)-Fa-H126-D3/32 Cantik, yang dilafazkan oleh Farhana. Kata cantik dalam dialog tersebut merupakan persetujuan secara langsung Farhana terhadap pertanyaan Fuad dalam dialog MR-B12(13)-Fu-H126D3/37 Cantik tak? yang merujuk kepada kad yang diberikan oleh Fuad kepada Farhana. Persetujuan secara langsung juga terdapat dalam dialog MR-B12(13)-FaH127-D7/32 Tentulah aku suka yang dituturkan oleh Farhana bagi menjawab pertanyaan Fuad dalam dialog MR-B12(13)-Fu-H127-D8/37 Kau suka tak? dan dalam dialog MR-B12(13)-Fu-H126-D6/37 Ya ... Betul, Fuad pula bersetuju secara langsung dengan Farhana apabila melafazkan kata ya dan disusuli kata betul apabila Farhana mengatakan Fuad yang memberikan kad tersebut. Persetujuan secara langsung dalam peristiwa ini bukan sahaja dapat melancarkan komunikasi malah dapat memaksimumkan persetujuan antara diri sendiri dengan orang lain yang sekali gus memanifestasikan kemesraan antara satu sama lain.

Peristiwa ini juga memperlihatkan kehadiran Maksim Kuantiti dalam komunikasi antara Fuad dan Farhana. Dialog MR-B12(13)-Fa-H126-D2/32 Merah jambu yang dituturkan oleh Farhana bagi menjawap pertanyaan Fuad dalam dialog MR-B12(13)-Fu-H126-D2/38 Warna apa? mencerminkan maklumat yang mencukupi apabila ditanya tentang warna kad yang diterima. Dialog MR-B12(13)Fu-H126-D4/37 Kau tahu siapa yang bagi? yang dituturkan oleh Fuad dan dijawab Farhana dalam dialog MR-B12(13)-Fa-H126-D4/32 Tahu juga memenuhi permintaan penutur dan dialog MR-B12(13)-Fu-H126-D5/37 Siapa? yang dituturkan oleh Fuad dan jawapan Farhana dalam dialog MR-B12(13)-Fa-H126D5/32 Engkaulah, mencerminkan sumbangan maklumat yang cukup dan memenuhi kehendak melalui pertanyaan atau permintaan sekali gus mewujudkan kerjasama dalam berkomunikasi. Penutur memperlihatkan sikap berhati-hati agar maklumat yang diberikan tidak berlebihan kerana maklumat yang berlebihan akan mengundang kebosanan kepada pendengar. Pemberian maklumat yang mencukupi dalam berkomunikasi mematuhi maksim Kuantiti dalam PK Grice dalam memanifestasikan kerjasama dan kesopanan berbahasa. 
Berdasarkan perbincangan di atas, didapati peristiwa ini memperlihatkan struktur tertentu dalam memaparkan kesopanan berbahasa seperti dalam Jadual 4 yang berikut:

\begin{tabular}{|l|l|l|}
\hline Peristiwa & Unsur & Kebijaksanaan \\
\hline \multirow{3}{*}{$\begin{array}{l}\text { Fuad memberikan kad } \\
\text { harijadi kepada Farhana }\end{array}$} & Unsur sapaan & Kuantiti \\
\cline { 2 - 3 } & $\begin{array}{l}\text { Unsur pertanyaan } \\
\text { Unsur pernyataan }\end{array}$ & Persetujuan \\
\cline { 2 - 3 } & $\begin{array}{l}\text { Unsur pernyataan } \\
\text { Unsur pernyataan }\end{array}$ & \\
\cline { 2 - 3 } & Unsur pernyataan & Kerendahan Hati \\
\cline { 2 - 3 } & $\begin{array}{l}\text { Unsur pertanyaan } \\
\text { Unsur lawak } \\
\text { Unsur pernyataan }\end{array}$ & Persetujuan \\
\hline
\end{tabular}

Berdasarkan Jadual 3, mukadimah perbualan dimulakan oleh Fuad dengan menggunakan unsur sapaan bagi menyapa Farhana melalui penggunaan kata nama peribadi iaitu, Ana sebelum meneruskan perbualan bagi memperlihatkan kebijaksanaan berbahasa selain mengundang kemesraan dalam perbualan. Seterusnya, barulah Fuad bertanya dengan menggunakan unsur pertanyaan bagi mendapatkan kuantiti maklumat yang mencukupi. Farhana pula menggunakan unsur pernyataan bagi memberikan maklumat yang ditanya Fuad tentang kad yang diberi oleh Fuad. Unsur yang sama juga digunakan oleh Fuad untuk mendapatkan maklumat, iaitu respons daripada Farhana sama ada kad itu cantik dan sama ada Farhana menyukainya atau tidak. Farhana menggunakan unsur pernyataan bagi memberikan maklumat yang diminta. Bagi memperlihatkan persetujuan dalam komunikasi, unsur pernyataan digunakan oleh Fuad dan Farhana apabila Fuad mengiakan dia yang memberikan kad tersebut. Seterusnya, Fuad menggunakan unsur pernyataan melalui ungkapan negatif murah saja empat ringgit setengah untuk mengakui kerendahan hatinya bahawa kad yang diberinya murah. Akhirnya, bagi mendapatkan persetujuan sekali lagi tentang reaksi Farhana sama ada menyukai kad tersebut atau tidak, Fuad menggunakan unsur pertanyaan dan unsur lawak. Tujuan Fuad berbuat demikian adalah untuk memancing perhatian Farhana dan mewujudkan kemesraan di samping menghiburkan hati. Farhana menggunakan unsur pernyataan dengan mengakui bahwa dia menyukai kad tersebut lebih-lebih lagi Fuad yang memberinya. Unsur sapaan, pertanyaan, pernyataan, pertanyaan dan lawak digunakan dalam peristiwa ini untuk mencerminkan kesopanan berbahasa selain mencapai objektif komunikasi, iaitu Fuad hendak mengetahui reaksi Farhana terhadap kad yang diberinya sempena harijadi Farhana. 


\section{Pola Kombinasi Maksim Kebijaksanaan+Kerendahan Hati+Persetujuan- Peristiwa 2: Fuad Mengajak Farhana Keluar Berjalan}

Pola kombinasi Maksim Kebijaksanaan+Kerendahan Hati+Persetujuan ditandai kata kunci yang tertentu. Maksim Kebijaksanaan ditandai pemilihan kata yang tepat untuk mendekati dan berurusan dengan seseorang dan menggunakan kata yang sesuai dan sopan untuk memanggil rakan sekerja. Maksim Kerendahan Hati ditandai sikap merendah diri, iaitu mencaci diri sendiri sementara Maksim Persetujuan ditandai dengan kewujudan kesepakatan yang tinggi. Kesemua dialog ini dianalisis berdasarkan peristiwa dalam novel ini. Pola kombinasi Maksim Kebijaksanaan+Kerendahan Hati+Persetujuan ini dapat dilihat dalam peristiwa Fuad mengajak Farhana keluar berjalan seperti dalam Jadual 5 yang berikut:

\begin{tabular}{|l|l|}
\hline \multicolumn{1}{|c|}{ Pola Kombinasi Maksim } & Kebijaksanaan+Kerendahan Hati + Persetujuan \\
\hline MR-B12(13)-Fu-H127-D9/37 & $\begin{array}{l}\text { Ana, duduk kejap. Tak mahu ucap terima kasihkah? } \\
\text { Aku tahulah kad aku tu murah. } \\
\text { Okey, terima kasih. } \\
\text { An-B12(13)-Fa-H127-D8/32 } \\
\text { AR-B12(13)-Fu-H127-D10/37 } \\
\text { Ani. Itu pun kalau kau nak. } \\
\text { MR-B12(13)-Fa-H127-D9/32 }\end{array}$ \\
\hline
\end{tabular}

Perbualan dalam peristiwa ini mematuhi Maksim Kebijaksanaan + Persetujuan + Sokongan + Kerendahan Hati. Maksim Kebijaksanaan dikenal pasti melalui sikap sopan meminta rakan duduk untuk berbicara. Fuad dalam dialog MR-B12(13)-Fu-H127-D9/37 Ana, duduk kejap, meminta Farhana duduk sekejap supaya dia dapat bericara dengan Farhana. Ungkapan duduk kejap merupakan permintaan yang beradab dan memudahkan perbualan dan pendengar juga berasa selesa. Pemilihan kata yang tepat untuk berurusan dengan orang lain juga terserlah melalui tindakan yang bijaksana untuk mencadang. Fuad dalam dialog MR-B12(13)-Fu-H127-D10/37 Ana, err ...Aku ingat nak ajak kau jalan-jalan petang ni. Itu pun kalau kau nak, bercadang untuk mengajak Farhana keluar. Kata kalau dan ingat dalam dialog ini merupakan penanda untuk mencadangkan sesuatu dan penggunaan kata melalui cara yang berhemah ini tidak akan memberi tekanan kepada pendengarnya, iaitu Farhana kerana lebih lembut dan sopan. Pemilihan dan penggunaan kata yang tepat dan sesuai untuk meminta dan mencadangkan sesuatu bukan sahaja mencerminkan kesopanan berbahasa malah dapat meminimumkan kos pendengar dalam berkomunikasi.

Peristiwa ini juga memaparkan penggunaan kata ganti nama yang sesuai seperti kata ganti nama peribadi, iaitu Ana yang lebih lembut dan sopan di 
samping penggunaan kata ganti nama $\boldsymbol{a} \boldsymbol{k} \boldsymbol{u}$ dan $\boldsymbol{k a u}$. Penggunaan kata ganti nama $a k u$ dan $k a u$ antara Farhana dan Fuad masih sopan kerana faktor keakraban hubungan mereka.

Maksim Kerendahan Hati pula terdapat dalam dialog MR-B12(13)-FuH127-D9/37 Aku tahulah kad aku tu murah yang dilafazkan oleh Fuad. Kata sifat murah yang dilafazkan oleh Fuad mengimplikasikan cacian terhadap dirinya sendiri kerana sanggup mengakui bahawa kad yang dibelinya murah. Berdasarkan maksim ini, sikap menyelar, menghina, mengkritik dan mengakui kelemahan diri merupakan tindakan yang sopan kerana cacian terhadap diri sendiri dapat diterima sebagai sopan walaupun berlebihan (Leech, 1993: 164).

Maksim Persetujuan dalam peristiwa ini dipatuhi apabila Farhana menyetujui cadangan Fuad yang hendak mengajaknya keluar dalam dialog MRB12(13)-Fa-H127-D9/32 Petang ni ... bolehlah. Setakat jalan-jalan apa salahnya. Kata bolehlah dalam dialog ini memanifestasikan persetujuan secara langsung Farhana terhadap cadangan Fuad. Persetujuan juga terdapat dalam dialog MR-B12(13)-FaH127-D8/32 Okey, terima kasih, yang dituturkan oleh Farhana bagi menyetujui permintaan Fuad dalam dialog MR-B12(13)-Fu-H127-D9/37 Tak mahu ucap terima kasihkah? Penutur yang sopan sentiasa berusaha untuk mewujudkan kesepakatan dalam berkomunikasi agar dapat memaksimumkan persetujuan antara diri sendiri dengan orang lain di samping menjaga air muka lawan tuturnya.

Berdasarkan perbincangan di atas, didapati peristiwa ini memperlihatkan struktur tertentu dalam memaparkan kesopanan bahasa seperti dalam Jadual 6 yang berikut:

\begin{tabular}{|l|l|l|}
\hline Peristiwa & Unsur & \\
\hline \multirow{2}{*}{$\begin{array}{l}\text { Fuad mengajak } \\
\text { Farhana } \\
\text { berjalan }\end{array}$} & $\begin{array}{l}\text { Unsur sapaan } \\
\text { Unsur permintaan }\end{array}$ & Kebijaksanaan \\
\cline { 2 - 3 } & Unsur pernyataan & Kerendahan Hati \\
\cline { 2 - 3 } & $\begin{array}{l}\text { Unsur pertanyaan } \\
\text { Unsur pernyataan }\end{array}$ & Persetujuan \\
\cline { 2 - 3 } & \begin{tabular}{l} 
Unsur sapaan \\
Unsur cadangan \\
\cline { 2 - 3 }
\end{tabular} & Kebijaksanaan \\
\hline
\end{tabular}

Berdasarkan Jadual 4, mukadimah perbualan dimulakan oleh Fuad dengan menggunakan unsur sapaan, iaitu dengan menggunakan kata nama peribadi untuk menyapa rakan bagi menggambarkan kebijaksanaan berbahasa. Kemudian barulah Fuad menggunakan unsur permintaan dengan meminta Farhana duduk. Seterusnya, Fuad menggunakan unsur pernyataan untuk memberitahu bahawa kad yang diberinya murah bagi menggambarkan kerendahan hati. Selepas itu 
barulah Fuad menggunakan unsur pertanyaan untuk mendapatkan persetujuan Farhana agar mengucapkan terima kasih kepadanya. Farhana menyatakan persetujuannya dengan mengucapkan teima kasih atas pemberian kad tersebut. Akhirnya, barulah Fuad menyatakan cadangannya untuk membawa Farhana keluar bersiar-siar. Farhana memberikan persetujuan dengan menyatakan kesudiannya untuk keluar berjalan-jalan. Unsur sapaan, permintaan, penyataan, pertanyaan dan cadangan digunakan dalam peristiwa ini bagi menggambarkan kesopanan berbahasa selain mencapai objektif komunikasi, iaitu Fuad berjaya menyampaikan hajatnya hendak membawa Farhana bersiar-siar.

\section{(iii) Pola Kombinasi Maksim Kebijaksanaan+Sokongan+Kerendahan Hati+Relevan- Peristiwa 3: Perbualan Semasa Memesan Makanan}

Pola kombinasi Maksim Kebijaksanaan+Sokongan+Kerendahan Hati+Relevan ditandai kata kunci yang tertentu. Maksim Kebijaksanaan ditandai pemilihan kata yang tepat untuk memanggil rakan sekerja dan cara yang berhemah untuk berurusan dengan seseorang manakala Maksim Sokongan ditandai oleh kata pujian dalam perbualan. Maksim Kerendahan Hati ditandai sikap merendah diri dengan memohon maaf dan menolak pujian sementara Maksim Relevan pula ditandai sumbangan maklumat yang mempunyai pertalian dengan permintaan atau pertanyaan. Kesemua dialog ini dianalisis berdasarkan peristiwa dalam novel ini. Pola kombinasi Maksim Kebijaksanaan+Sokongan+Kerendahan Hati+Relevan ini dapat dilihat dalam peristiwa semasa memesan makanan seperti dalam Jadual 7 yang berikut:

\begin{tabular}{|l|l|}
\hline \multicolumn{1}{|c|}{ Pola Maksim/Peristiwa } & $\begin{array}{l}\text { Kebijaksanaan+Sokongan+ } \\
\text { Kerendahan Hati+Relevan }\end{array}$ \\
\hline MR-B12(13)-Fu-H128-D11/37 & $\begin{array}{l}\text { Kau nak makan apa Ana? } \\
\text { Ikut kaulah. Aku ikut saja, orang nak belanjalah katakan. } \\
\text { Apa fasal kau pandang aku macam tu? Aku lupa pakai } \\
\text { gincukah? } \\
\text { MR-B12(13)-Fu-H128-D12/37 } \\
\text { MR-B12(13)-Fa-H128-D11/32 } \\
\text { MR-B12(13)-Fu-H128-D13/37 }\end{array}$ \\
$\begin{array}{l}\text { Tohonglah. Sebab kau cantik. } \\
\text { La ... Tak percaya? Kalau tak percaya, balik rumah nanti } \\
\text { jangan lupa tengok cermin. }\end{array}$ \\
\hline
\end{tabular}

Perbualan dalam peristiwa ini mematuhi Maksim Kebijaksanaan + Sokongan + Kerendahan Hati + Relevan. Maksim Kebijaksanaan diperlihatkan melalui pemilihan kata yang sesuai dan lembut dalam memberi cadangan, iaitu 
penggunaan kata kalau. Fuad memberi cadangan kepada Farhana agar melihat cermin apabila balik dalam dialog MR-B12(13)-Fu-H128-D13/37 La ... Tak percaya? Kalau tak percaya, balik rumah nanti jangan lupa tengok cermin. Cadangan yang ditandai kata kalau dapat meminimumkan kos pendengar dalam komunikasi. Pemilihan kata yang tepat dan sesuai untuk memanggil rakan dalam peristiwa ini ditandai kata ganti nama $a k \boldsymbol{k}, \boldsymbol{k a u}$ dan kata ganti nama peribadi, iaitu Ana. Penggunaan kata ganti nama tersebut mencerminkan kesopanan berbahasa kerana digunakan oleh dua orang rakan yang akrab. Penggunaan kata ganti nama yang sesuai dapat memaksimumkan manfaat kepada pendengar.

Maksim Sokongan dalam peristiwa ini ditandai kata pujian dalam dialog MR-B12(13)-Fu-H128-D12/37 Sebab kau cantik. Kata sifat cantik yang dituturkan oleh Fuad dalam dialog ini mencerminkan pujian dan menunjukkan Farhana seorang gadis yang cantik. Penutur, iaitu Fuad berusaha memaksimumkan pujian terhadap orang lain dalam berkomunikasi bagi mengekspresi kesopanan berbahasa dan tindakan ini dapat menyenangkan hati pendengar dalam berkomunikasi kerana tiada sesiapa yang suka dikeji.

Penolakan terhadap pujian merupakan penanda bagi Maksim Kerendahan Hati dalam peristiwa ini. Farhana dalam dialog MR-B12(13)-Fa-H128-D11/32 Bohonglah, menolak pujian Fuad yang mengatakannya cantik. Kata bohonglah dalam dialog ini bermakna tidak benar dan Farhana tidak menerima pujian dengan mudah. Penolakan terhadap pujian mencerminkan sikap rendah diri dan sikap tidak bermegah-megah dengan pujian. Penolakan ini bukan sahaja melambangkan kesopanan berbahasa malahan meminimumkan pujian terhadap diri sendiri.

Maksim Relevan dalam peristiwa ini terdapat dalam dialog MR-B12(13)Fa-H128-D10/32 Ikut kaulah. Aku ikut saja, orang nak belanjalah katakan. Ayat yang dituturkan oleh Farhana dalam dialog ini memberikan sumbangan maklumat yang mempunyai pertalian dengan pertanyaan Fuad dalam dialog MR-B12(13)Fu-H128-D11/37 Kau nak makan apa Ana? Jawapan yang diberikan oleh Farhana, Ikut kaulah. Aku ikut saja, orang nak belanjalah katakan, secara tersiratnya berkaitan dengan pertanyaan Fuad tentang apa yang hendak dimakan oleh Farhana walaupun jawapannya langsung tidak berkaitan dengan makanan. Walau bagaimanapun, jawapannya difahami dan Fuad bebas untuk memesan makanan. Sumbangan maklumat yang mempunyai pertalian dengan perkara yang disoal amat bermakna untuk mewujudkan kerjasama dalam berkomunikasi dan sekali gus memanifestasikan kesopanan berbahasa.

Berdasarkan perbincangan di atas, didapati peristiwa ini memperlihatkan struktur tertentu dalam memaparkan kesopanan berbahasa seperti dalam Jadual 8 yang berikut: 


\begin{tabular}{|l|l|l|}
\hline Peristiwa & Unsur & Relevan \\
\hline $\begin{array}{l}\text { Perbualan semasa } \\
\text { memesan makanan }\end{array}$ & $\begin{array}{l}\text { Unsur pertanyaan } \\
\text { Unsur pernyataan }\end{array}$ & \\
\cline { 2 - 3 } & Unsur pujian & Sokongan \\
\cline { 2 - 3 } & Unsur penafian & Kerendahan Hati \\
\cline { 2 - 3 } & $\begin{array}{l}\text { Unsur cadangan } \\
\text { Unsur lawak }\end{array}$ & Kebijaksanaan \\
\hline
\end{tabular}

Berdasarkan Jadual 5, mukadimah perbualan dimulakan oleh Fuad dengan menggunakan unsur pertanyaan bagi mendapatkan maklumat yang relevan daripada Farhana, iaitu tentang makanan yang hendak dipesan. Farhana memberikan maklumat yang relevan dengan menggunakan unsur pernyataan. Seterusnya, Fuad menggunakan unsur pujian bagi memuji Farhana apabila Farhana bertanyakan sebab Fuad memandangnya. Sementara Farhana menggunakan unsur penafian apabila dipuji Fuad bagi mencerminkan kerendahan hatinya. Akhirnya, Fuad menggunakan unsur cadangan dan unsur lawak dengan memberi cadangan kepada Farhana agar melihat dirinya di cermin jika tidak percaya akan pujian Fuad. Unsur pertanyaan, pernyataan, pujian, penafian, cadangan dan lawak digunakan dalam peristiwa ini untuk menggambarkan kesopanan berbahasa selain mencapai objektif komunikasi, iaitu untuk mewujudkan suasana yang mesra ketika memesan makanan.

\section{Kesimpulan}

Berdasarkan analisis, didapati tiga pola kombinasi maksim yang terbentuk dan pola kombinasi maksim yang tertinggi ialah pola kombinasi Maksim Kebijaksanaan + Kerendahan Hati + Persetujuan + Kuantiti, iaitu sebanyak 60.87 peratus sementara pola kombinasi maksim yang terendah ialah pola kombinasi Maksim Kebijaksanaan + Kerendahan Hati + Persetujuan, iaitu sebanyak 17.39 peratus. Hasil analisis ini memperlihatkan kedua-dua model ini sesuai untuk menganalisis data kajian.

Selain itu, penelitian juga memperlihatkan bahawa struktur pola kesopanan berbahasa disampaikan dalam struktur yang bervariasi. Walaupun hasil dapatan memperlihatkan penggunaan pola-pola tertentu tetapi struktur dalam peristiwa-peristiwa tersebut berbeza antara satu sama lain. Perkara ini berlaku disebabkan setiap peristiwa komunikasi mempunyai objektif yang tersendiri. Impaknya, penyusunan struktur bagi setiap peristiwa adalah berbezabeza bagi mencapai objektif komunikasi.

Maksim Kebijaksanaan disampaikan dengan penggunaan unsur sapaan, unsur permintaan dan unsur cadangan. Penggunaan unsur sapaan untuk memulakan 
perbualan dapat mempamerkan kebijaksanaan dalam berbahasa dan memperlihatkan kecenderungan yang dominan. Unsur sapaan berperanan sebagai penghubung antara penutur dengan pendengar dan menjadi unsur wacana yang dominan dalam peristiwa komunikasi. Penutur dan pendengar menggunakan kata panggilan dan sapaan yang sesuai dalam berkomunikasi yang mencakupi kata ganti nama diri pertama seperti saya, kata ganti nama diri kedua seperti awak dan kata nama peribadi. Asmah Hj Omar (1993: 81) menyatakan kata ganti nama saya, kami dan kita merupakan kata ganti nama pertama yang paling biasa dan diterima oleh semua golongan. Ganti nama tersebut adalah santun.

Maksim Sokongan pula disampaikan dengan menggunakan unsur pujian bagi mencerminkan sokongan dan penghargaan apabila penutur memuji dan berasa kagum dengan seseorang. Ketiadaan unsur ini akan mengimplikasikan cacian walaupun harus dilakukan secara berpada-pada. Maksim Kerendahan Hati memperlihatkan penggunaan unsur penafian dan unsur pernyataan. Unsur penafian digunakan untuk menolak pujian bagi memberi gambaran kerendahan hati seseorang. Tindakan menafikan pujian mencitrakan kehalusan budi bahasa kerana dalam sesebuah masyarakat, penolakan atau penafian terhadap pujian adalah cerminan masyarakat yang sopan. Unsur pernyataan pula digunakan untuk memaklum atau mengekspresikan sikap rendah diri.

Maksim Persetujuan dipatuhi dengan menggunakan unsur pertanyaan bagi memperolehi persetujuan. Penggunaan unsur ini merupakan pendekatan yang sesuai untuk mendapatkan persetujuan agar tidak mengimplikasikan paksaan. Maksim Kuantiti dalam kajian ini memperlihatkan penggunaan unsur lawak, unsur pertanyaan dan unsur pernyataan. Unsur lawak diselitkan dalam perbualan agar peristiwa komunikasi menjadi lebih mesra dan tidak tegang serta dapat membangkitkan perasaan terhibur dan komunikasi berjalan dengan tenang. Penggunaan unsur pertanyaan berkesan untuk mendapatkan maklumat yang mencukupi dalam komunikasi. Secara fitrahnya, setiap pertanyaan pasti diikuti jawapan sekiranya wujud kerjasama dan kesopanan dalam berbahasa. Menurut Mohamad Fadzeli Jaafar (2013: 240) penggunaan ujaran pertanyaan lebih memberi kesan khususnya dalam memulakan sesuatu perbualan. Maksim Relevan pula memperlihatkan penggunaan unsur pertanyaan dan pernyataan. Unsur pernyataan dalam hal ini berperanan untuk mencerminkan sumbangan maklumat yang mempunyai pertalian agar dapat meningkatkan kerjasama dan sekali gus memanifestasikan kesopanan.

Novel Melunas Rindu memperlihatkan paparan kesopanan berbahasa dan struktur peristiwa kesopanan berbahasa yang signifikan sekali gus memperlihatkan kesesuaian novel ini sebagai teks Komsas. Para murid mendapat pendedahan tentang aspek kesopanan bertitik tolak daripada penggunaan bahasa yang sopan dan tepat selain penggunaan struktur pola kesopanan berbahasa yang bervariasi untuk mencapai objektif komunikasi. Lanjutan daripada itu, kita dapat 
melahirkan generasi yang peka dalam membudayakan bahasa yang sopan dan sesuai dengan situasi atau peristiwa komunikasi.

\section{Nota Hujung}

${ }^{1}$ Pengkaji menggunakan istilah murid dalam kajian ini untuk merujuk kepada pelajar sekolah menengah berdasarkan istilah yang digunakan dalam Sukatan Pelajaran Bahasa Melayu walaupun penggunaan murid biasanya dirujuk kepada mereka yang belajar di sekolah rendah.

${ }^{2}$ Komsas ialah singkatan bagi Komponen Sastera dalam mata pelajaran Bahasa Melayu yang mulai diperkenalkan di seluruh sekolah menengah di Malaysia mulai tahun 2000. Fasa pertama (2000-2009) dan sekarang fasa kedua yang bermula pada tahun 2010 dengan menggunakan teks dan antologi yang baharu.

${ }^{3}$ Novel Melunas Rindu mula digunakan oleh para murid Tingkatan Empat di Zon 4 (Johor, Sarawak, Sabah dan Wilayah Persekutuan Labuan mulai tahun 2010 bagi menggantikan novel Terminal Tiga (2000-2009) karya Othman Puteh.

${ }_{4}$ Dalam Falsafah Pendidikan Kebangsaan dinyatakan dengan jelas bahawa matlamat pendidikan negara adalah untuk melahirkan insan yang seimbang dan harmoni dari segi intelek, rohani, emosi dan jasmani berdasarkan kepercayaan dan kepatuhan kepada Tuhan (Kementerian Pendidikan Malaysia, 2001).

\section{Rujukan}

Asmah Hj Omar. (1993). Nahu Melayu mutakhir edisi keempat. Kuala Lumpur: Dewan Bahasa dan Pustaka.

Azman Ismail. (2010). Mencari kekuatan bahasa dan sastera kebangsaa. Dewan Bahasa. Oktober, hlm. 15-18.

Grice, H.P. (1975). Logic and conversations. Dlm. Cole, P., \& Morgan (ed.) Syntax and Semantic: Speech Act. New York: Academic Press, 41-58.

Haris Abd. Wahab. (2004). Masalah sosial di bandar Semenanjung Malaysia: Tinjauan daripada Perspektif Masyarakat Malaysia. JATI, UM, 9. Disember, hal. 55-74.

Hartini Hamzah. (2009). Melunas rindu edisi murid. Utusan Publication \& Distributors Sdn. Bhd: Kementerian Pelajaran Malaysia.

Kementerian Pendidikan Malaysia. (2001). Falsafah pendidikan kebangsaan: Matlamat dan misi. Kuala Lumpur: Pusat Perkembangan Kurikulum Kementerian Pendidikan Malaysia.

Khan, Qaisar \& Ali Bughio, Faraz. (2012). Nunnery scene: A pragmatic analysis of Hamlet-Ophelia encounter. 3L: Language, Linguistics and Literature, The Southeast Asean Journal of English Language Studies, 18(2). pp.25-34. ISNN 0128-5157 
Leech, Geoffrey. (1983). Principles of pragmatics. New York: Longman.

Leech, Geoffrey. (1993). Prinsip pragmatik. Terj. Azhar M. Simin. Kuala Lumpur: Dewan Bahasa dan Pustaka.

Mior Ahmad Noor Mior Hamzah. (2003). Bangsa Melayu: Melihat sebuah tamadun sebagaimana yang digambarkan oleh karya sejarah Melayu. JATI, UM, 8. Disember, hal 155-182.

Mohamad Fadzeli Jaafar. (2013). Teori sistemik-fungsional dalam stilistik. Kuala Lumpur: Dewan Bahasa dan Pustaka.

Mohamad Khairi Othman \& Asmawati Suhid. (2010). Peranan sekolah dan guru dalam pembangunan nilai pelajar menerusi penerapan nilai murni: Satu sorotan. MALIM, SEA Journal of General Studies, 11, 117-130.

Naffi Mat. (2006). Keperluan teks sastera dalam pengajaran Bahasa Melayu. Dewan Bahasa. September: 44-47.

Tenas Effendy. (2011). Kesantunan dan semangat Melayu. Pemerintah Kota Pekanbaru \& Tenas Effendy Foundation: Pekanbaru. 